summary from January 1992 through June 2004, issued October 2004 Am J Infect Control 2004; 32:470-485.

9. Chuang SC, Lee KT, Chang WT, et al. Risk factors for wound infection after cholecystectomy. $J$ Formos Med Assoc 2004; 103:607-612.

10. Williams LF, Jr., Chapman WC, Bonau RA, McGee EC, Jr., Boyd RW, Jacobs JK. Comparison of laparoscopic cholecystectomy with open cholecystectomy in a single center. Am J Surg 1993; 165:459-465.

\section{Reply to Chen et al.}

T O THE EDITOR-We really appreciate the interest of Dr. Chen and colleagues ${ }^{1}$ in our recent article. ${ }^{2}$ Several factors may explain the lower rate of laparoscopic cholecystectomy in our institutions. It is not the consequence of higher rates of conversion to open cholecystectomy, because we kept converted procedures in their original surgical group. First, note that our institutions adopted the National Nosocomial Infection Surveillance (NNIS) system's definition of operative procedure, which excludes outpatient (same-day) surgical procedures. ${ }^{3}$ Thus, same-day laparoscopic cholecystectomies were excluded from the analysis, lowering the overall proportion of laparoscopic procedures. Furthermore, our increasing use of same-day laparoscopic cholecystectomy in recent years, similar to increases in the use of this procedure elsewhere around the world, can account for the apparent reduction in the proportion of laparoscopic cholecystectomy observed in our series over time. Second, the use of miniincision cholecystectomy as an alternative approach to both open cholecystectomy and laparoscopic cholecystectomy is rising in frequency in our country. For surveillance purposes, we consider classic laparotomic cholecystectomies and miniincision cholecystectomies to be open cholecystectomies. So, inclusion of data on procedures with mini-incision access would lower the rate of laparoscopic cholecystectomy but leave the rate of open cholecystectomy unchanged.

Third, recall that our institutions are private and not university affiliated, and major differences exist in clinical practices in comparison to public or university-affiliated hospitals. Although economic concerns are obviously not unique to the private sector, the economic pressures exerted by health plans assume a clear role in private institutions, particularly in a resource-constrained country such as ours. Economic evaluations conducted in developed countries have so far favored laparoscopic cholecystectomy over open cholecystectomy, but the cost savings of laparoscopic cholecystectomy may be less apparent in other types of institutions ${ }^{4}$ or when compared with minilaparotomy cholecystectomy. ${ }^{5}$ Moreover, some ways in which laparoscopic cholecystectomy has demonstrated clear superiority over open cholecystectomy, such as shorter associated sick leave, do not necessarily represent a clear benefit to health plans and, accordingly, do not enter in their cost-effectiveness equations. More importantly, even with the assumption that laparoscopic cholecystectomy is cost effective, laparoscopic cholecystectomy savings may not overcome the increased consumption of healthcare resources resulting from the well-known rise in the number of cholecystectomies performed and in hospital use after laparoscopic cholecystectomy is introduced. ${ }^{6-8}$ It is possible that all of these concerns may have limited the availability of laparoscopy in our institutions to some extent.

That our study might have been underpowered to detect a lower risk of organ space infections after laparoscopic cholecystectomy was acknowledged in the Discussion section of our article. ${ }^{2}$ Chen et al. ${ }^{1}$ declined to assess the risk of organ space infection in their study, so the assertion that our finding differs from their experience is not supported by their data. It is misleading to consider the study by Richards et al. ${ }^{9}$ as valid evidence of reduced risk of organ space infection following laparoscopic cholecystectomy. The lower crude rate of organ space infection after laparoscopic cholecystectomy reported in that study was an unadjusted comparison and, therefore, was not mentioned as a major finding by the authors. ${ }^{9}$ In that study, patients who underwent laparoscopic cholecystectomy were obviously less prone to infection than patients who underwent open cholecystectomy, because laparoscopic cholecystectomies were shorter in duration, and patients who underwent these procedures were younger and less likely to have an American Society of Anesthesiologists classification of 3 or greater, dirty or contaminated wounds, emergency procedures, or multiple procedures performed through the same incision. ${ }^{9}$ Therefore, laparoscopic cholecystectomy and open cholecystectomy could not be straightforwardly compared without a multivariate analysis, which was only provided for the overall risk of surgical site infection (SSI). ${ }^{9}$ We still believe that, if our extensive cohort of 5,848 patients failed to show a difference in the risk of organ space infection, a potential difference seems to be clinically irrelevant in our setting.

Chen et al.' should note that more caution in needed when comparing the SSI rates we reported ${ }^{2}$ with those of the NNIS system. The most obvious reason for the higher SSI rate in our cohort was the higher proportion of open cholecystectomies. Second, the NNIS system emphasizes that, for SSI rate comparisons to be valid, it must be known whether case finding included infections detected after discharge and the postdischarge surveillance method must be the same ${ }^{10}$; however, their own reports repeatedly fail to declare whether postdischarge surveillance was actually used and what proportion of patients were reached by postdischarge surveillance. ${ }^{11}$ Chen et al. ${ }^{1}$ also did not mention whether postdischarge surveillance was used in their study. Therefore, any comparison between their SSI rates and ours is irrelevant, and inferences about the generalizability of our data based on such comparisons are hasty and inaccurate. In our study, 55.5\% of all SSIs were detected after discharge, even though a modest $49.5 \%$ of patients were reached by postdischarge surveillance. ${ }^{2}$ In the study by Richards et al., ${ }^{9}$ only $28.8 \%$ of SSIs were 
detected after discharge, suggesting that the proportion of patients reached by out-of-hospital surveillance in that study, and in NNIS hospitals as a whole, is even less than that in our study. What renders our practice incomparable to that of most hospitals in the United States is, first of all, irreconcilable differences in surveillance methods.

For these reasons, we agree with Chen et al. ${ }^{1}$ that our results must not be generalized to patients in the United States, and to the same extent, the results of US studies must not be generalized to our patients. It is not clear why they suggest that a study could be generalized to a population other than that from which the sample was retrieved.

Chen et al. ${ }^{1}$ should explain further why it may not be possible to use data on the risk of SSI collected prior to 2000 in a cohort study with concurrent controls. This concern may be more relevant for a study using historical controls. Increases in conversion rates are mainly driven by changes in the spectrum of indications for laparoscopic cholecystectomy. ${ }^{12}$ The inclusion of the year of surgery as explanatory variable was the only possible means to address this in our data.

\section{ACKNOWLEDGMENTS}

Financial support. F.M.B. reports receiving grant support N\$0151041 from Capes/CNPq- IEL Nacional-Brasil for the original manuscript.

Potential conflicts of interest. The author reports no conflicts of interest relevant to this article.

Fernando M. Biscione, MD, MSc

From the Health Sciences Postgraduate Course, Medicine High School, Minas Gerais Federal University, Belo Horizonte, Minas Gerais, Brazil.

Address reprint requests to Fernando M. Biscione, MD, MSc, 190 Alfredo Balena av., Suite 7003, Santa Efigênia, Belo Horizonte, Minas Gerais, Brazil, 31.130-100 (fernandobiscione@yahoo.com.ar).

Infect Control Hosp Epidemiol 2008; 29:94-95

(C) 2007 by The Society for Healthcare Epidemiology of America. All rights reserved. 0899-823X/2008/2901-0020\$15.00.DOI: 10.1086/524912

\section{REFERENCES}

1. Chen LF, Anderson DJ, Hartwig MG, Kaye, KS, Sexton DJ. Surgical site infections after laparoscopic and open cholecystectomies in community hospitals. Infect Control Hosp Epidemiol 2008; 29:92-94 (in this issue).

2. Biscione FM, Couto RC, Pedrosa TM, Neto MC. Comparison of the risk of surgical site infection after laparoscopic cholecystectomy and open cholecystectomy. Infect Control Hosp Epidemiol 2007; 28:1103-1106.

3. Horan TC, Emori TG. Definitions of key terms used in the NNIS system. Am J Infect Control 1997; 25:112-116.

4. Teerawattananon $Y$, Mugford $M$. Is it worth offering a routine laparoscopic cholecystectomy in developing countries? A Thailand case study. Cost Eff Resour Alloc 2005; 3:10.

5. Nilsson E, Ros A, Rahmqvist M, Backman K, Carlsson P. Cholecystectomy: costs and health-related quality of life: a comparison of two techniques. Int J Qual Health Care 2004; 16:473-482.

6. Hobbs MS, Mai Q, Fletcher DR, Ridout SC, Knuiman MW. Impact of laparoscopic cholecystectomy on hospital utilization. ANZ I Surg 2004; $74: 222-228$
7. Legorreta AP, Silber JH, Costantino GN, Kobylinski RW, Zatz SL. Increased cholecystectomy rate after the introduction of laparoscopic cholecystectomy. JAMA 1993; 270:1429-1432.

8. McMahon AJ, Fischbacher CM, Frame SH, MacLeod MC. Impact of laparoscopic cholecystectomy: a population-based study. Lancet 2000; 356:1632-1637.

9. Richards C, Edwards J, Culver D, Emori TG, Tolson J, Gaynes R. Does using a laparoscopic approach to cholecystectomy decrease the risk of surgical site infection? National Nosocomial Infections Surveillance System, Centers for Disease Control and Prevention. Ann Surg 2003; 237: 358-362.

10. Mangram AJ, Horan TC, Pearson ML, Silver LC, Jarvis WR. Guideline for prevention of surgical site infection, 1999. Hospital Infection Control Practices Advisory Committee. Infect Control Hosp Epidemiol 1999; 20: 250-278.

11. National Nosocomial Infections Surveillance (NNIS) system report, data summary from January 1992 through June 2004, issued October 2004. Am J Infect Control 2004; 32:470-485.

12. Ishizaki Y, Miwa K, Yoshimoto J, Sugo H, Kawasaki S. Conversion of elective laparoscopic to open cholecystectomy between 1993 and 2004 Br J Surg 2006; 93:987-991.

\section{Are We "Squeezing The Balloon" When Reducing the Risk of Occupational Infection? Reply to Pan et al.}

TO THE E DI TOR-Under a witty title, Pan et al. ${ }^{1}$ described a needlestick injury that occurred while a cytopathologist was performing fine-needle aspiration cytology (FNAC) using the modified method that I and my colleagues proposed ${ }^{2}$ to eliminate the needle manipulation involved in classical FNAC. They relate that the needle shot out when the cytopathologist depressed the plunger to extract the material obtained by aspiration, and they suggest a possible cause: the needle was clogged by a colloidal clot aspirated from a thyroid nodule. Unfortunately, the needle bounced and lodged in the cytopathologist's scalp. With no other argumentation, they assume that clot aspiration is inherent to the modified method of FNAC and so is a new injury risk associated with use of the modified method.

I agree that a clot might have clogged the needle and caused the accident. Nevertheless, I don't know the physical law that explains why aspiration of a clot is only possible when using the modified FNAC technique and not when using the conventional FNAC method. Also, the reason for which the needle's odd flight path and its unlucky ending must be considered an exclusive result of the modified FNAC method eludes me. My personal experience includes more than 6,500 FNAC procedures, more than 3,500 of which were performed with the modified method. Although I cannot determine the exact number, I have had a few experiences with both classical and modified FNAC in which the needle shot out suddenly when I depressed the plunger. Fortunately, no injury ever followed. Finally, I don't see the line of argument by which Pan et 